\title{
Belphégor
}

\section{Santa, Àngels, La literatura popular francesa: folletines y melodramas}

Lleida, Pagès editors i Universitat de Lleida, co. “El Fil d'Ariadna”, 2012. p. 196.

\section{Carme Figuerola}

\section{(2) OpenEdition}

Journals

Edición electrónica

URL: http://journals.openedition.org/belphegor/166

DOI: $10.4000 /$ belphegor.166

ISSN: 1499-7185

Editor

LPCM

\section{Referencia electrónica}

Carme Figuerola, «Santa, Àngels, La literatura popular francesa: folletines y melodramas », Belphégor [En ligne], 11-1 | 2013, mis en ligne le 28 avril 2013, consulté le 22 septembre 2020. URL : http://

journals.openedition.org/belphegor/166 ; DOI : https://doi.org/10.4000/belphegor.166

Este documento fue generado automáticamente el 22 septiembre 2020.

\section{(c)}

Belphégor est mis à disposition selon les termes de la Licence Creative Commons Attribution - Pas d'Utilisation Commerciale - Pas de Modification 4.0 International. 


\section{Santa, Àngels, La literatura popular francesa: folletines y melodramas}

Lleida, Pagès editors i Universitat de Lleida, co. “El Fil d'Ariadna”, 2012. p. 196.

\section{Carme Figuerola}

\section{REFERENCIA}

Àngels Santa, La literatura popular francesa: folletines y melodramas, Lleida, Pagès editors i Universitat de Lleida, co. "El Fil d'Ariadna", 2012. p. 196 
1 Faltaríamos a la verdad si mantuviéramos que el campo de la literatura popular sigue constituyendo un ámbito poco explorado por la crítica literaria. Desde los años 80 se ha prodigado un considerable incremento en la atención a la escritura "popular" así como a la industria cultural, en gran parte heredera de los mecanismos que caracterizaron a su antepasada. Desde los análisis de Jean-Claude Vareille, de Michel Nathan, hasta las iniciativas que hoy en día lleva la Association internationale des Chercheurs en Littératures Populaires et Cultures Médiatiques al frente de la cual figura su presidente Jacques Migozzi se suceden especialistas prestigiosos que han convertido este género, si así puede llamarse, en centro de su labor investigadora (Charles Grivel, Jean-Yves Mollier, Daniel Couégnas, Paul Bleton, por citar a unos pocos). Pese a los avances

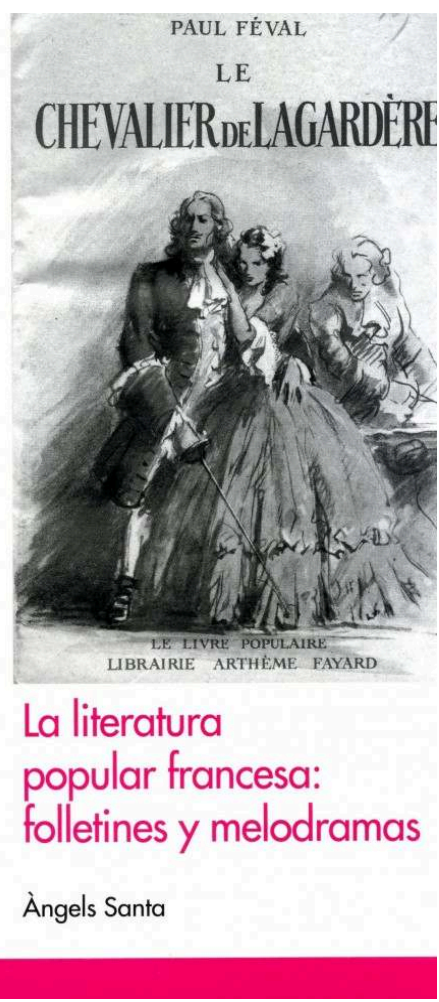
logrados la etiqueta de lo popular recubre un corpus profuso y diverso en el que todavía queda mucho por descubrir. En el caso de España también nuestro país cuenta ya con una cierta tradición en este tipo de estudios. Ana González, Antonio Altarriba, Elena Real, Lola Jiménez y la misma Àngels Santa constituyen nombres de referencia para quienes se interesan por el tema. Esa experiencia en la investigación es la que permite a la autora la obra que aquí se presenta lograr una síntesis rigurosa y amena.

2 Conforme al espíritu divulgativo que anima la colección "El Fil d'Ariadna", el volumen de Àngels Santa tomo como punto de partida establecer una definición de la novela popular considerando las distintas posturas críticas que la han tomado como objeto de estudio y a la vez, a modo introductorio, sintetizar los rasgos que la caracterizan. Se centra luego en dos manifestaciones: el folletín francés y el melodrama. Guiada por un espíritu marcadamente didáctico, detalla los aspectos distintivos de cada subgénero, se detiene asimismo en la consideración de las formas que éstos pueden adoptar (novela marítima, novela frenética, novela histórica en el caso del folletín...) sin descuidar sus antecedentes (la tragedia y los mismos folletines en cuanto a los melodramas). Persiguiendo un acercamiento sistemático a esa realidad en la obra se especifican las circunstancias sociológicas que favorecen y explican el auge de tales productos: la progresiva difusión de la prensa en el lectorado de la Francia decimonónica o el desarrollo de la imagen como elemento de promoción figuran como elementos susceptibles de explicar una difusión masiva del folletín que contrasta, en cambio con la escasa recepción crítica. El análisis contempla también, en lo relativo al melodrama, aspectos específicos de la vida teatral: desde los avatares de las salas parisinas, de sus protagonistas -los actores- hasta elementos materiales trascendentes para las escenificaciones del orden de los decorados o la música que suelen acompañar las representaciones y que vehiculan por otros canales el mensaje emitido por el autor. 
Con todo, ambas manifestaciones literarias distan de ser realidades monolíticas según demuestra el presente volumen al especificar las sucesivas etapas que atestiguan y marcan la evolución de los respectivos géneros. Tampoco podía faltar una mención a los autores más representativos: los más conocidos Eugène Sue, Paul Féval, Alexandre Dumas conviven con otros tales como Xavier de Montepin, Emile Richebourg, Pierre Decourcelle o Charles Merouvel en lo tocante al folletín; Pixérécourt, Louis Caigniez, Adolphe Dennery, entre otros, protagonizan el capítulo dedicado al melodrama. Para cada uno de ellos Àngels Santa procede consignando los aspectos biográficos más relevantes, para centrarse luego en las aportaciones innovadoras relativas a su campo. Con todo y pese a las limitaciones que impone un volumen con una finalidad divulgativa, la especialista rehúye las fórmulas de la historia literaria al uso y efectúa su contribución personal determinando cuál puede ser el interés de tales obras entre el público actual. Con el ánimo de facilitar la lectura, un índice nominal sintetiza en breves párrafos el caudal literario de los escritores mencionados en el cuerpo del trabajo. Asimismo para los menos iniciados se ha concebido un breve glosario de términos frecuentemente utilizados en el análisis crítico además de una tabla cronológica que compara acontecimientos sociopolíticos relevantes y su contexto cultural con eventos destacados en la literatura popular para subrayar con ello la coexistencia de este tipo de literatura con las producciones tradicionalmente consideradas como "canónicas".

4 Además del estilo claro que facilita la lectura del libro, la autora ha optado por acompañar el texto de numerosas ilustraciones nada baladíes puesto que, como ella misma afirma, ya en su día la imagen ejerció una función trascendente en lo relativo a dicha industria cultural. Otro apartado meritorio radica en la selección de textos críticos que se aportan para refrendar los argumentos teóricos presentados: el pensamiento de Antoine Court, Charles Grivel, Jules Janin, Jean-Marie Thomasseau... resuena como eco que completa las tesis de la obra. Otras voces encuentran también cabida en el volumen y, eliminando intermediarios, remiten a la creación misma puesto que se presentan fragmentos de las obras más representativas de los autores citados. Entre éstas no faltan ejemplos de Los Tres mosqueteros, ni de Los misterios de París, ni de Felipe Derblay, ni de El Jorobado.

5 Para completar el volumen la consiguiente bibliografía transcribe referencias de análisis relacionados con el contenido que motiva la obra. No obstante, otro mérito de esta bibliografía consiste en establecer un buen número de volúmenes de revistas centrados exclusivamente en el tema y cuya repercusión a menudo se diluyen cuando aparecen citados de forma fragmentaria por los artículos que contienen.

En suma, la novela popular encuentra en la presente edición un volumen esmerado donde se mesura la importancia de sus distintos apartados para conseguir una panorámica rigurosa sin por ello olvidar que este tipo de literatura debió su éxito al afán por la lectura... De ahí que a través de los fragmentos escogidos no dude en ofrecernos una invitación a la misma, un breve pero exquisito aperitivo que despierte en el lector el ansia de conocer el resto de las peripecias que guían a tales protagonistas. Nada que objetar si tenemos en cuenta que para aprehender y apreciar la calidad literaria, al menos en una primera instancia, es más que recomendable embeberse de ella. 